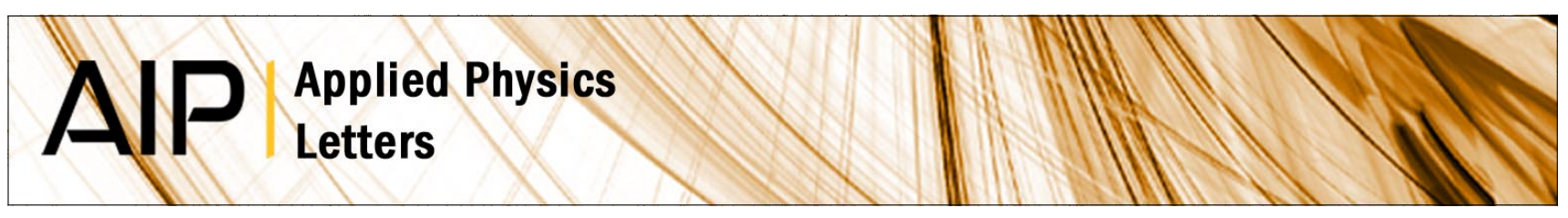

\title{
p-channel thin-film transistors based on spray-coated Cu2O films
}

Pichaya Pattanasattayavong, Stuart Thomas, George Adamopoulos, Martyn A. McLachlan, and Thomas D.

Anthopoulos

Citation: Appl. Phys. Lett. 102, 163505 (2013); doi: 10.1063/1.4803085

View online: http://dx.doi.org/10.1063/1.4803085

View Table of Contents: http://apl.aip.org/resource/1/APPLAB/v102/i16

Published by the AIP Publishing LLC.

\section{Additional information on Appl. Phys. Lett.}

Journal Homepage: http://apl.aip.org/

Journal Information: http://apl.aip.org/about/about_the_journal

Top downloads: http://apl.aip.org/features/most_downloaded

Information for Authors: http://apl.aip.org/authors

\section{ADVERTISEMENT}
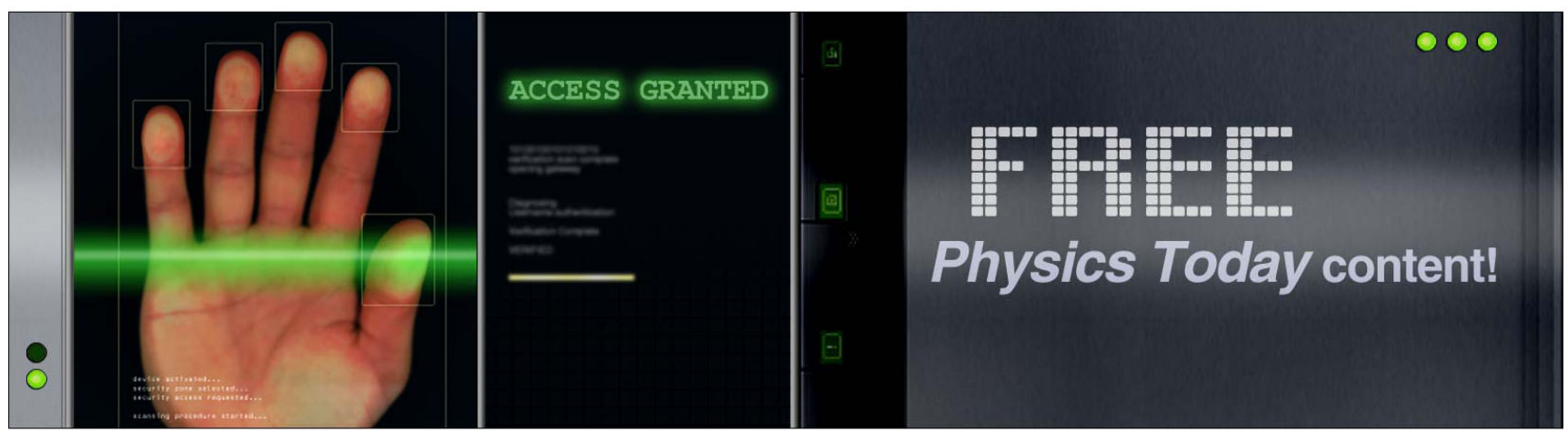


\title{
p-channel thin-film transistors based on spray-coated $\mathrm{Cu}_{2} \mathrm{O}$ films
}

\author{
Pichaya Pattanasattayavong, ${ }^{1}$ Stuart Thomas, ${ }^{1}$ George Adamopoulos, ${ }^{2}$ \\ Martyn A. McLachlan, ${ }^{3}$ and Thomas D. Anthopoulos ${ }^{1, a)}$ \\ ${ }^{1}$ Centre for Plastic Electronics and Department of Physics, Blackett Laboratory, Imperial College London, \\ London SW7 2BW, United Kingdom \\ ${ }^{2}$ Department of Engineering, Lancaster University, Lancaster LAI 4YR, United Kingdom \\ ${ }^{3}$ Centre for Plastic Electronics and Department of Materials, Imperial College London, London SW7 2AZ, \\ United Kingdom
}

(Received 31 December 2012; accepted 14 April 2013; published online 26 April 2013)

\begin{abstract}
Thin films of cuprous oxide $\left(\mathrm{Cu}_{2} \mathrm{O}\right)$ were grown using solution-based spray pyrolysis in ambient air and incorporated into hole-transporting thin-film transistors. The phase of the oxide was confirmed by X-ray diffraction measurements while the optical band gap of the films was determined to be $\sim 2.57 \mathrm{eV}$ from optical transmission measurements. Electrical characterization of $\mathrm{Cu}_{2} \mathrm{O}$ films was performed using bottom-gate, bottom-contact transistors based on $\mathrm{SiO}_{2}$ gate dielectric and gold source-drain electrodes. As-prepared devices show clear p-channel operation with field-effect hole mobilities in the range of $10^{-4}-10^{-3} \mathrm{~cm}^{2} \mathrm{~V}^{-1} \mathrm{~s}^{-1}$ with some devices exhibiting values close to $1 \times 10^{-2} \mathrm{~cm}^{2} \mathrm{~V}^{-1} \mathrm{~s}^{-1}$. (C) 2013 AIP Publishing LLC. [http://dx.doi.org/10.1063/1.4803085]
\end{abstract}

The rapid advances in the development of electrontransporting (n-type) oxide semiconductors such as $\mathrm{ZnO}$, $\mathrm{SnO}_{2}$, and $\mathrm{In}_{2} \mathrm{O}_{3}$ are pushing forward the realization of alloxide electronics. ${ }^{1}$ Such technologies create the possibility of preparing high charge carrier mobility devices via scalable and low-cost manufacturing processes-making them ideal candidates for application in large-area microelectronics. ${ }^{2,3}$ Despite tremendous potential, further advancements have been hampered by a lack of hole-transporting (p-type) oxides with similar or comparable transport characteristics to their n-type counterparts. Although there are a handful of studies reporting p-type doping of traditional n-type oxides, ${ }^{4}$ the subject still remains controversial as doping of metal oxides is typically one-sided (i.e., n-type materials are only dopable with donors) due to self-compensation. ${ }^{5,6}$ Hence, alternative metal oxides that show intrinsic p-type characteristics are required. To date, only a few such compounds, e.g. $\mathrm{SnO}_{\mathrm{x}}$ and $\mathrm{Cu}_{2} \mathrm{O}$, have been demonstrated and incorporated into p-type thin-film transistors (TFTs). $\mathrm{SnO}_{\mathrm{x}}$ has received significant attention in recent years mainly because of the high hole field-effect mobility $\left(\mu_{h, F E}\right)$ on the order of $0.1-1 \mathrm{~cm}^{2} \mathrm{~V}^{-1} \mathrm{~s}^{-1},^{7-12}$ as well as the observation of ambipolar charge transport. ${ }^{13}$ However, the highest reported $\mu_{h, F E}$ to date has been obtained from $\mathrm{Cu}_{2} \mathrm{O}$ transistors reaching values around $4.3 \mathrm{~cm}^{2} \mathrm{~V}^{-1} \mathrm{~s}^{-1} \cdot{ }^{14,15}$ More recently, Yao et al. also reported on $\mathrm{Cu}_{2} \mathrm{O}$ TFTs on flexible substrates with $\mu_{h, F E}$ of $2.4 \mathrm{~cm}^{2} \mathrm{~V}^{-1} \mathrm{~s}^{-1} \cdot{ }^{16}$ Collectively, these results reaffirm that the desired field-effect mobility of $>1 \mathrm{~cm}^{2} \mathrm{~V}^{-1} \mathrm{~s}^{-1}$ is generally achievable with $\mathrm{Cu}_{2} \mathrm{O}$ transistors.

The hole transport properties of $\mathrm{Cu}_{2} \mathrm{O}$ are attributed to the energetically favorable electron accepting defects (i.e., copper vacancies $-\mathrm{V}_{\mathrm{Cu}}$ ) and the dominant $\mathrm{Cu} 3 d$ character near the valence band maximum (VBM). ${ }^{5,17}$ The latter leads to a more dispersive valence band (VB) compared to those of other oxide semiconductors, particularly electron-transporting ones which strongly feature the localizing $\mathrm{O} 2 p$ character near their

\footnotetext{
${ }^{\text {a) }}$ Author to whom correspondence should be addressed. Electronic mail: t.anthopoulos@ic.ac.uk.
}

VBM. ${ }^{18}$ These characteristics give rise to high hole mobility in $\mathrm{Cu}_{2} \mathrm{O}$, with Hall effect measurements commonly showing mobilities exceeding $100 \mathrm{~cm}^{2} \mathrm{~V}^{-1} \mathrm{~s}^{-1}$ (Refs. 14 and 19) and even as high as $256 \mathrm{~cm}^{2} \mathrm{~V}^{-1} \mathrm{~s}^{-1}$. ${ }^{20}$ These results emphasize $\mathrm{Cu}_{2} \mathrm{O}$ as one of the promising choices for p-channel components in oxide electronics. In order to prepare $\mathrm{Cu}_{2} \mathrm{O}$ thin film, the most straightforward way is the controlled oxidation of a precursor $\mathrm{Cu}$ layer ${ }^{21,22}$ or using more advanced variations such as radical oxidation by $\mathrm{O}_{2}$ plasma, ${ }^{23}$ all of which are simple methods that could produce good quality $\mathrm{Cu}_{2} \mathrm{O}$ films. However, for device fabrication, the need to obtain high fieldeffect mobility along with the multiple-phase nature of $\mathrm{Cu}-\mathrm{O}$ material system $\left(\mathrm{Cu}, \mathrm{Cu}_{2} \mathrm{O}\right.$, and $\left.\mathrm{CuO}\right)$ have led to the focus on complex vacuum-based deposition techniques such as pulsedlaser deposition (PLD) ${ }^{14,24}$ and sputtering ${ }^{25,26}$ with the aim to produce single-phase, high-quality $\mathrm{Cu}_{2} \mathrm{O}$ films for transistor applications. These methods, however, rely on stringent experimental conditions and are incompatible with high-throughput manufacturing processes, especially when compared to solution-based deposition techniques. To this end, solution processing is scalable and hence cost-effective and could potentially offer a genuine alternative processing method for the manufacturing of large-area microelectronics based on oxide semiconductors. Despite the great potential, however, solution processed p-type $\mathrm{Cu}_{2} \mathrm{O}$ transistors have yet to be demonstrated.

Here, we report the fabrication of hole-transporting $\mathrm{Cu}_{2} \mathrm{O}$ thin-film transistors from spray pyrolysis (SP) performed in ambient air. Our group has recently employed SP for the sequential deposition of n-type $\mathrm{ZnO}$ and high- $k \mathrm{ZrO}_{2}$ dielectric layers to produce transistors with high electron field-effect mobilities. $^{27,28}$ Therefore, the ability to prepare high-quality p-type materials by SP can be seen as a significant step in the evolution of this technique as a robust tool for the development of next generation large-area microelectronics. The deposition of thick $\mathrm{Cu}_{2} \mathrm{O}$ films by $\mathrm{SP}$ has already been demonstrated by Kosugi and Kaneko. ${ }^{29}$ Their approach relies on the use of an aqueous precursor solution of copper(II) acetate monohydrate $\left(\mathrm{Cu}\left(\mathrm{CH}_{3} \mathrm{COO}\right)_{2} \cdot \mathrm{H}_{2} \mathrm{O}\right)$, glucose, and isopropyl 
alcohol (IPA) sprayed onto heated substrates. Glucose acts to reduce $\mathrm{Cu}$ (II) to $\mathrm{Cu}(\mathrm{I})$, which can then form $\mathrm{Cu}_{2} \mathrm{O}$ at a certain range of temperatures while IPA is added to improve the wettability of the solution and the overall film uniformity. This early work showed that growth of $>95 \% \mathrm{Cu}_{2} \mathrm{O}$ is possible under certain experimental conditions (Table I). Based on this simple procedure, we herein demonstrate p-type transistors from solution-processed films of $\mathrm{Cu}_{2} \mathrm{O}$.

Films of $\mathrm{Cu}_{2} \mathrm{O}$ were grown by spray pyrolysis onto $\mathrm{Si}^{++} / \mathrm{SiO}_{2}$ and quartz glass substrates using a $0.04 \mathrm{M}$ $\mathrm{Cu}\left(\mathrm{CH}_{3} \mathrm{COO}\right)_{2} \cdot \mathrm{H}_{2} \mathrm{O}, 0.04 \mathrm{M}$ glucose and 40 vol. \% IPA as the precursor solution. Spray pyrolysis of the active layers was carried out using a Sono-Tek ExactaCoat system with an ultrasonic spray nozzle. The process was performed in ambient air at a substrate temperature of $275^{\circ} \mathrm{C}$ with the following conditions: solution feed rate of $1.5 \mathrm{ml} \mathrm{min}^{-1}, \mathrm{~N}_{2}$ carrier gas pressure of 2 bars, and nozzle speed of $70 \mathrm{~mm} \mathrm{~s}^{-1}$. The cycle was repeated until the desired thickness of approximately $40 \mathrm{~nm}$ (measured by a Dektak profilometer) was obtained. The SP steps were followed by $12 \mathrm{~h}$ anneal at $200^{\circ} \mathrm{C}$ to improve the quality of the deposited films. It should be noted that this annealing temperature is below the conversion temperature of $\mathrm{Cu}_{2} \mathrm{O}$ to $\mathrm{CuO}$ which occurs at around $300{ }^{\circ} \mathrm{C}^{29,30}$ The crystal structure of $\mathrm{Cu}_{2} \mathrm{O}$ films was determined from X-ray diffraction (XRD) measurements using a PANalytical X'pert MPD diffractometer equipped with an accelerator detector $(40 \mathrm{kV}, 40 \mathrm{~mA})$. Film surface morphology was investigated using atomic force microscopy (AFM) employing an Agilent 5500 in tapping mode. UVvisible-near-infrared (UV-Vis-NIR) transmission spectra for $40 \mathrm{~nm} \mathrm{Cu}_{2} \mathrm{O}$ films deposited on quartz substrates were recorded using a Shimadzu UV-2550 spectrophotometer. Bottom-gate, bottom-contact (BG-BC) transistors were fabricated using heavily doped $\mathrm{Si}^{++}$wafers with a $200 \mathrm{~nm}$ thick thermally grown $\mathrm{SiO}_{2}$ gate dielectric containing prepatterned $10 \mathrm{~nm} / 30 \mathrm{~nm}$ ITO/gold as source/drain (S/D) electrodes. Device fabrication was completed with the deposition of $40 \mathrm{~nm}$ thick films of $\mathrm{Cu}_{2} \mathrm{O}$ directly onto the wafers. Electrical characterization of transistors was performed using a semiconductor parameter analyzer under high vacuum in the dark. The hole field-effect mobility was evaluated using the gradual channel approximation model in the saturation regime. The threshold voltage $\left(V_{T H}\right)$ was extracted from the $\mathrm{x}$-intercept of the plot between the square root of saturation drain current $\left(\sqrt{I_{D}}\right)$ and gate voltage $\left(V_{G}\right)$. Sub-threshold swing $(S)$ was estimated from $S=d V_{G} / d \log \left(I_{D}\right)$ whilst the trap density per unit energy $\left(D_{t r}\right)$ was estimated from

TABLE I. Summary of deposition parameters for spray pyrolysis process which yields $>95 \% \mathrm{Cu}_{2} \mathrm{O}$.

\begin{tabular}{lc}
\hline \hline Parameters ${ }^{\mathrm{a}}$ & $\begin{array}{c}\text { Condition for the synthesis } \\
\text { of }>95 \% \mathrm{Cu}_{2} \mathrm{O}\end{array}$ \\
\hline $\begin{array}{l}\text { Copper(II) acetate monohydrate } \\
\text { concentration, C }\end{array}$ & $<0.05 \mathrm{M}$ \\
Substrate temperature, $\mathrm{T}\left({ }^{\circ} \mathrm{C}\right)$ & $700 \sqrt{C}+128<T<150 \sqrt{C}+251$ \\
Glucose concentration & $0.04 \mathrm{M}$ \\
Amount of added isopropyl alcohol & 40 vol. $\%$ \\
\hline \hline
\end{tabular}

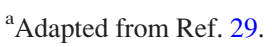

$D_{t r}=C_{i}\left[(S / 2.3 e k T)-1 / e^{2}\right]$, where $C_{i}$ is the geometric capacitance of the dielectric, $e$ is the elementary charge, $k$ is Boltzmann constant, and $T$ is the temperature.

The XRD measurements obtained from as-sprayed and annealed $\mathrm{Cu}_{2} \mathrm{O}$ films are shown in Figure 1, along with reference data for $\mathrm{Cu}_{2} \mathrm{O}$ and $\mathrm{CuO}$ powders. The broad background at low angles $\left(20^{\circ}-40^{\circ} 2 \theta\right)$ is attributed to the amorphous glass substrate. The peaks observed at $29.44^{\circ}, 36.50^{\circ}, 42.39^{\circ}$, $61.58^{\circ}$, and $73.77^{\circ}$ correspond to diffraction from the (110), (111), (200), (220), and (311) planes of $\mathrm{Cu}_{2} \mathrm{O}$, respectively. From this diffraction data, the (111) and (200) peaks conclusively confirm that the oxide formed from SP exists as $\mathrm{Cu}_{2} \mathrm{O}$ without secondary phases, i.e., $\mathrm{Cu}$ or $\mathrm{CuO}$ (within the detection limit of XRD), both before and after annealing. The effects of annealing are not strongly pronounced in the XRD data, with only marginal increases in peak intensities and minor reductions in peak widths observed. The calculated average crystallite size before and after annealing increases from $\mathrm{d}_{111}=11.3 \mathrm{~nm}$ to $\mathrm{d}_{111}=11.6 \mathrm{~nm}$. Similarly, the surface morphologies of the annealed and non-annealed films are comparable as evident in the AFM images shown in Figures 2(a) and 2(b). Grain statistics obtained from the AFM data [Figure 2(c)] show a lateral grain size of approximately $18 \mathrm{~nm}$ for both annealed and non-annealed films. Interestingly, a small reduction in the calculated standard deviation from $5.5 \mathrm{~nm}$ to $4.9 \mathrm{~nm}$ before and after annealing is observed. The latter is also accompanied by a decrease in the root-mean-square (r.m.s.) surface roughness from $3.53 \mathrm{~nm}$ to $2.73 \mathrm{~nm}$ before and after annealing. Both observations suggest that the low-temperature annealing is improving the uniformity and homogeneity of the deposited films without the introduction of unwanted secondary phases.

The optical transmission spectra of as-sprayed and annealed $\mathrm{Cu}_{2} \mathrm{O}$ films also show very similar characteristics. Figure 3 shows the UV-Vis-NIR transmission and absorption spectra for an annealed $\mathrm{Cu}_{2} \mathrm{O}$ film. The transmission spectrum of the annealed film is similar to previously published data, ${ }^{29,31}$ showing a significant absorption around $\sim 500 \mathrm{~nm}$ and a tail that extends to shorter wavelengths. The absorbance $(A)$ is calculated from the transmittance ( $T$ ) using $A=-\log \left(T / T_{0}\right)$, in

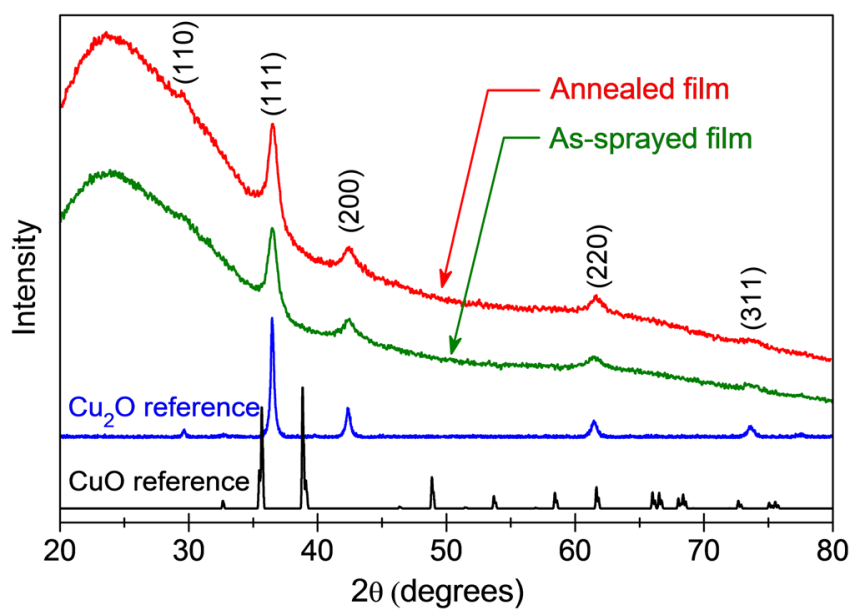

FIG. 1. XRD results of as-sprayed (green line) and annealed (red line) $\mathrm{Cu}_{2} \mathrm{O}$ films prepared from spray pyrolysis process. The XRD peaks can be attributed to $\mathrm{Cu}_{2} \mathrm{O}$ (110), (111), (200), (220), and (311) planes. Diffraction patterns of powder $\mathrm{Cu}_{2} \mathrm{O}$ (blue line) and $\mathrm{CuO}$ (black line) are also shown as references. 

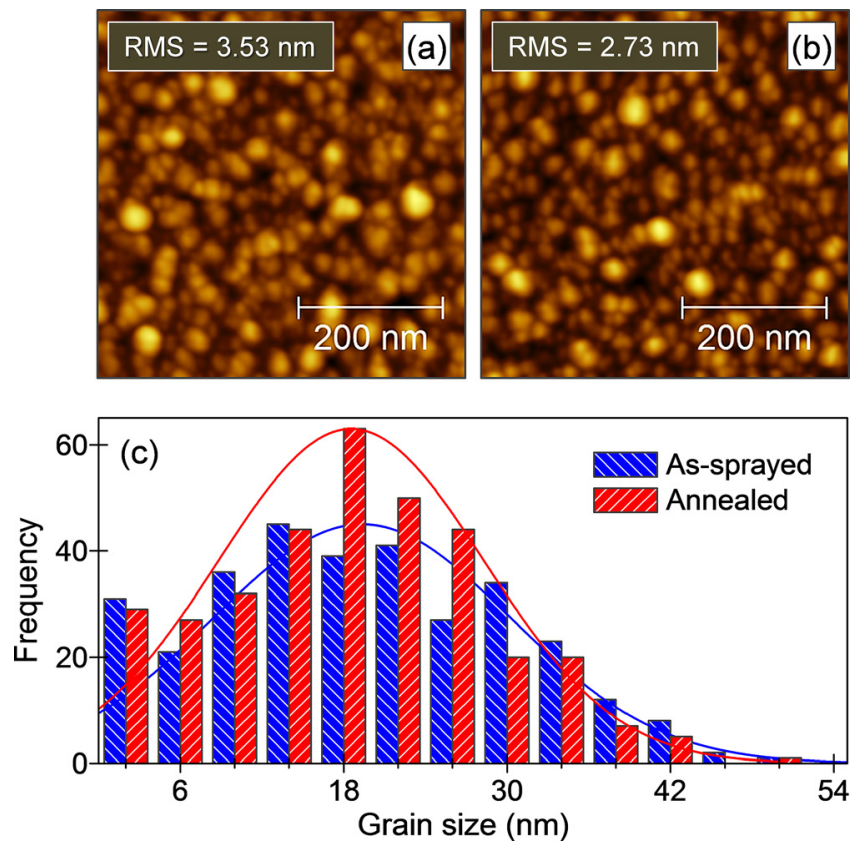

FIG. 2. Surface morphologies of (a) as-sprayed and (b) annealed $\mathrm{Cu}_{2} \mathrm{O}$ films from AFM displaying similar appearance before and after annealing. The average grain size in both cases is $18 \mathrm{~nm}$; however, grain statistics, shown as histograms in (c), suggest that post-deposition heat treatment improves the size distribution as seen from the decreasing standard deviation from $5.5 \mathrm{~nm}$ to $4.9 \mathrm{~nm}$ with annealing. Surface roughness (measured from the root-mean-square average of the topographic data) also decreases from $3.53 \mathrm{~nm}$ to $2.73 \mathrm{~nm}$.

order to calculate the optical band gap $\left(E_{\text {opt }}\right)$ of these films. The latter is extracted from the x-intercept of the plot between $(\alpha \mathrm{h} \nu)^{2}$ versus $\mathrm{h} \nu$ (inset in Figure 3), where $\alpha$ is the absorption coefficient, $h$ is Planck's constant, and $\nu$ is the optical frequency. For both as-sprayed and annealed films (40 nm thick), $E_{\text {opt }}$ is found to be a direct gap of $\sim 2.57 \mathrm{eV}$. Although the actual band gap of $\mathrm{Cu}_{2} \mathrm{O}$ is $2.1 \mathrm{eV}$, the lowest transition is not dipole-allowed due to the same parity of $\Gamma_{7}^{+}$(top of valence band) and $\Gamma_{6}^{+}$(bottom of conduction band) levels, and in fact the strong light absorption only occurs for $E>2.4 \mathrm{eV}$, which is the dipole-allowed transition between $\Gamma_{7}^{+}$(top of valence band) and $\Gamma_{8}^{-}$(second lowest conduction band). ${ }^{32,33}$ This consideration can also explain the presence of the tail below the main

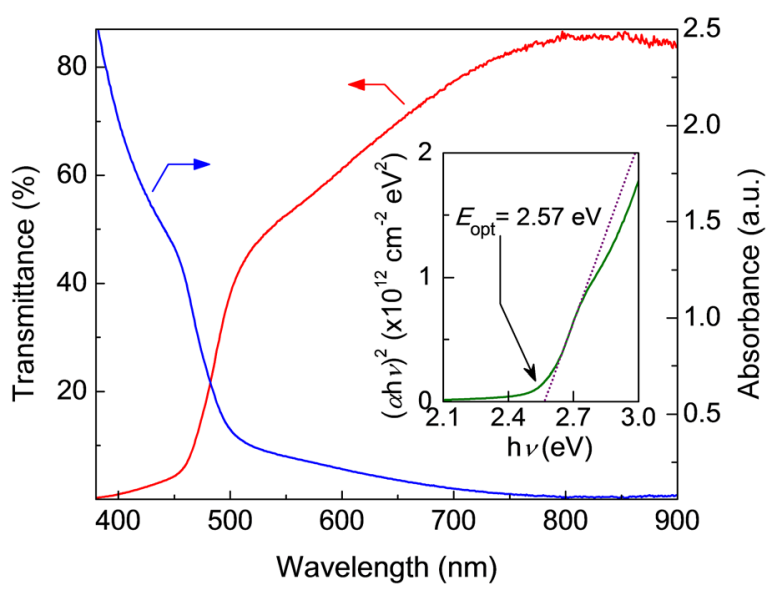

FIG. 3. Optical transmission (red line) and absorption (blue line) spectra of an annealed $\mathrm{Cu}_{2} \mathrm{O}$ thin film from spray pyrolysis. The absorption edge is approximately $500 \mathrm{~nm}$, which corresponds to a direct optical band gap $\left(E_{\text {opt }}\right)$ of $2.57 \mathrm{eV}$, extracted from the plot between $(\alpha \mathrm{h} \nu)^{2}$ and $\mathrm{h} \nu$ (inset). absorption edge at $500 \mathrm{~nm}$. The further shift toward higher photon energies may also be attributed to the quantum size effect as well as to defects and surface states present in these nanogranular $\mathrm{Cu}_{2} \mathrm{O}$ films. ${ }^{34}$ The reported value of $2.57 \mathrm{eV}$ here also agrees with other experimental values in literature, which range from 2.4 to $2.6 \mathrm{eV} .^{25,29,32}$

Bottom-gate, bottom-contact (BG-BC) transistors [Figure 4(a)] based on spray-coated $\mathrm{Cu}_{2} \mathrm{O}$ thin-films also show promising results. Although both as-sprayed and annealed films yielded working transistors, the annealing step improved the device performance by increasing the on/off ratio and hole field-effect mobility by approximately one order of magnitude. Figures 4(b) and 4(c) display a representative set of transfer and output characteristics measured from annealed $\mathrm{Cu}_{2} \mathrm{O}$-based transistors with channel width $(W)$ and length $(L)$ of $10 \mathrm{~mm}$ and $20 \mu \mathrm{m}$, respectively. The channel off-current, as seen from Figure 4(b), is around $1 \mathrm{nA}$ while the maximum oncurrent is close to $4-5 \mu \mathrm{A}$, yielding an on/off current ratio of $>4 \times 10^{3}$. The average hole field-effect mobility $\left(\mu_{h, F E}\right)$ calculated from 10 transistors is $\sim 3 \times 10^{-4} \mathrm{~cm}^{2} \mathrm{~V}^{-1} \mathrm{~s}^{-1}$ with some devices showing maximum values up to $1 \times 10^{-2}$ $\mathrm{cm}^{2} \mathrm{~V}^{-1} \mathrm{~s}^{-1}$. The threshold voltage $\left(V_{T H}\right)$ calculated from these devices is high and close to $-70 \mathrm{~V}$ while the average sub-threshold swing $(S)$ is $30 \mathrm{~V}$ decade ${ }^{-1}$, corresponding to a trap density $\left(D_{t r}\right)$ of $\sim 5.6 \times 10^{13} \mathrm{eV}^{-1} \mathrm{~cm}^{-2}$. The high values of $V_{T H}, S, D_{t r}$, and the low hole field-effect mobility are most likely attributed to the large number of grain boundaries and the presence of a significant density of hole-traps at the unpassivated $\mathrm{SiO}_{2} / \mathrm{Cu}_{2} \mathrm{O}$ interface. An additional source of defects may be attributed to some inclusion of $\mathrm{Cu}$ impurities, e.g., different oxidation states of $\mathrm{Cu}\left(\mathrm{Cu}^{0}\right.$ or $\left.\mathrm{Cu}^{2+}\right)$ which can exist as

(a)
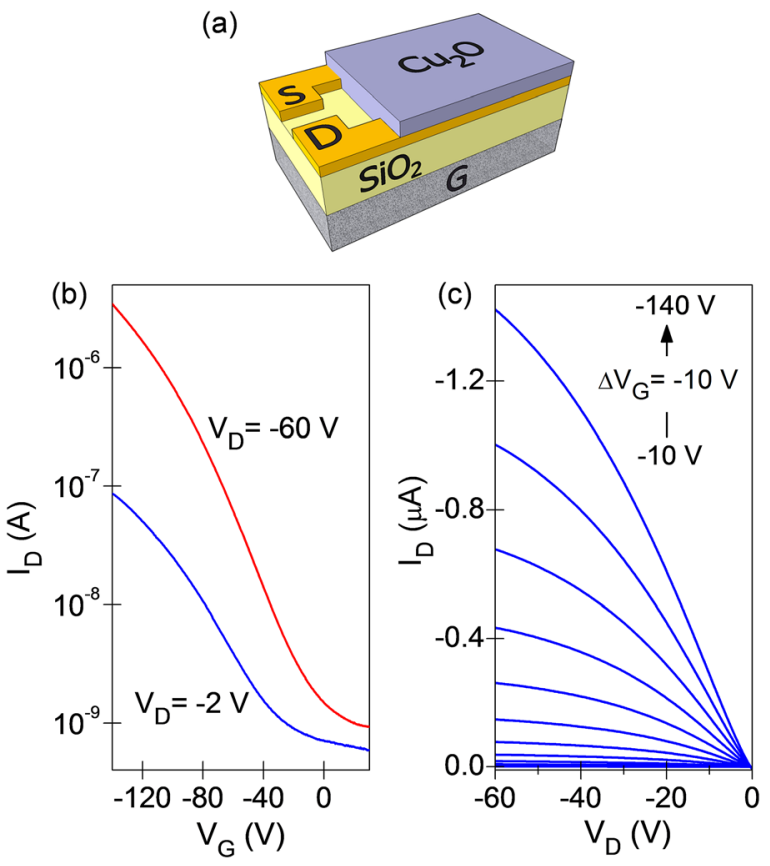

FIG. 4. (a) Schematic of the BG-BC transistor architecture used to study the charge transport properties of the spray-coated $\mathrm{Cu}_{2} \mathrm{O}$ films. The devices employ a heavily doped $\mathrm{Si}\left(\mathrm{Si}^{++}\right)$electrode acting as the common gate, a thermally grown layer of $\mathrm{SiO}_{2}$ acting as the gate dielectric and photolithographically patterned gold source/drain (S/D) electrodes as the hole-injecting contacts. A representative set of results from electrical characterization of $\mathrm{Cu}_{2} \mathrm{O}$ BG-BC TFTs showing (b) transfer and (c) output characteristics. The dimensions of the transistor studied here are $W=10 \mathrm{~mm}$ and $L=20 \mu \mathrm{m}$. 
point defects or phase-separated regions at concentrations too low to be detected by XRD. Further studies on the trapping mechanism and its relation to structural and chemical defects are expected to provide important information that could help improving the performance of solution-processed $\mathrm{Cu}_{2} \mathrm{O}$ TFTs and will be the subject of future investigations.

The demonstration of solution-processed $\mathrm{Cu}_{2} \mathrm{O}$ TFTs reported here clearly emphasizes that devices with performance level comparable to those obtained from $\mathrm{Cu}_{2} \mathrm{O}$ transistors fabricated using sophisticated vacuum-based and high temperature processing methods, is possible. Specifically, the hole field-effect mobilities in this work are not significantly lower than the values reported in literature. For example, the pioneering work on $\mathrm{Cu}_{2} \mathrm{O}$ TFTs from PLD and sputtering showed $\mu_{h, F E}$ of $0.26 \mathrm{~cm}^{2} \mathrm{~V}^{-1} \mathrm{~s}^{-1}$ and $1 \times 10^{-3} \mathrm{~cm}^{2} \mathrm{~V}^{-1} \mathrm{~s}^{-1}$, respectively. ${ }^{24,25}$ Future research on solution-processed $\mathrm{Cu}_{2} \mathrm{O}$ transistors should benefit from previous work on vacuum-processed $\mathrm{Cu}_{2} \mathrm{O}$ TFTs which has shown that hole mobility and switching characteristics can be significantly improved through optimization of the $\mathrm{Cu}_{2} \mathrm{O} /$ dielectric interface ${ }^{15}$ and by reducing $D_{t r}$ by 1-2 orders of magnitude. Also, Sohn et al. has recently shown that annealing $\mathrm{Cu}_{2} \mathrm{O}$ films in vacuum could promote further crystal growth and suppress carrier concentration, hence leading to smaller number of grain boundaries and higher hole mobility. ${ }^{35}$ In the case of spray pyrolysis, or solutionprocessing of $\mathrm{Cu}_{2} \mathrm{O}$, in general, further improvement might be achieved through optimization of the deposition process and research on alternative precursor chemistries, such that stoichiometric-pure $\mathrm{Cu}_{2} \mathrm{O}$ can be produced with high yield. Such improvements could lead to reduced background carrier concentration and hence higher on/off current ratio. To this end, Nagai et al. have recently developed a solutionprocessing precursor based on $\mathrm{Cu}^{2+}$ complex with ethylenediamine- $N, N, N^{\prime}, N^{\prime}$-tetraacetic acid and dibutylamine in ethanol and shown that the film is p-type $\mathrm{Cu}_{2} \mathrm{O}$ with Hall mobility of $4.8 \mathrm{~cm}^{2} \mathrm{~V}^{-1} \mathrm{~s}^{-1}$. ${ }^{36}$ Finally, improving the crystallinity of the $\mathrm{Cu}_{2} \mathrm{O}$ films may also improve both the hole mobility as well as the on/off current ratio of the transistors. In the case of $\mathrm{Cu}_{2} \mathrm{O}$ films grown by spray pyrolysis, such improvements could potentially be achieved through the use of alternative precursor compounds and/or by controlling the atmosphere during spray deposition.

In summary, we have demonstrated solution-processed p-channel $\mathrm{Cu}_{2} \mathrm{O}$-based thin-film transistors. $\mathrm{Cu}_{2} \mathrm{O}$ film deposition has been carried out using the spray pyrolysis technique in ambient air without any special precautions. As-prepared bottom-gate, bottom-contact transistors show clear p-channel operation with hole field-effect mobilities in the range $10^{-4}-10^{-3} \mathrm{~cm}^{2} \mathrm{~V}^{-1} \mathrm{~s}^{-1}$ and on/off channel current ratio exceeding $4 \times 10^{3}$. Best performing TFTs with hole mobilities up to $10^{-2} \mathrm{~cm}^{2} \mathrm{~V}^{-1} \mathrm{~s}^{-1}$ have also been obtained but were difficult to reproduce in large numbers. Despite this, the spray deposition approach described here is simple, scalable and inexpensive and offers a genuine alternative for the manufacturing of large-area oxide microelectronics based on complementary logic circuitry as well as other emerging optoelectronic devices such as thin-film photovoltaics. ${ }^{37}$
P.P. and T.D.A. thank Anandamahidol Foundation, Thailand, and Cambridge Display Technology (CDT), UK, for the financial support. T.D.A. is also grateful to European Research Council (ERC) AMPRO Project No. 280221 for the financial support.

${ }^{1}$ E. Fortunato, P. Barquinha, and R. Martins, Adv. Mater. 24(22), 2945 (2012).

${ }^{2}$ J. F. Wager, Science 300(5623), 1245 (2003).

${ }^{3}$ K. Bourzac, Nature 484(7394), 301 (2012).

${ }^{4}$ M. D. McCluskey and S. J. Jokela, J. Appl. Phys. 106(7), 071101 (2009).

${ }^{5}$ H. Raebiger, S. Lany, and A. Zunger, Phys. Rev. B 76(4), 045209 (2007).

${ }^{6}$ S. Lany and A. Zunger, Phys. Rev. Lett. 98(4), 045501 (2007).

${ }^{7}$ C.-W. Ou, Dhananjay, Z. Y. Ho, Y.-C. Chuang, S.-S. Cheng, M.-C. Wu, K.-C. Ho, and C.-W. Chu, Appl. Phys. Lett. 92(12), 122113 (2008).

${ }^{8}$ Y. Ogo, H. Hiramatsu, K. Nomura, H. Yanagi, T. Kamiya, M. Hirano, and H. Hosono, Appl. Phys. Lett. 93(3), 032113 (2008).

${ }^{9}$ L. Y. Liang, Z. M. Liu, H. T. Cao, Z. Yu, Y. Y. Shi, A. H. Chen, H. Z. Zhang, Y. Q. Fang, and X. L. Sun, J. Electrochem. Soc. 157(6), H598 (2010).

${ }^{10}$ E. Fortunato, R. Barros, P. Barquinha, V. Figueiredo, S.-H. K. Park, C.-S. Hwang, and R. Martins, Appl. Phys. Lett. 97(5), 052105 (2010).

${ }^{11}$ H. Yabuta, N. Kaji, R. Hayashi, H. Kumomi, K. Nomura, T. Kamiya, M. Hirano, and H. Hosono, Appl. Phys. Lett. 97(7), 072111 (2010).

${ }^{12}$ R. Martins, A. Nathan, R. Barros, L. Pereira, and P. Barquinha, Adv. Mater. 23(39), 4491 (2011).

${ }^{13}$ K. Nomura, T. Kamiya, and H. Hosono, Adv. Mater. 23(30), 3431 (2011).

${ }^{14}$ X. Zou, G. Fang, L. Yuan, M. Li, W. Guan, and X. Zhao, IEEE Electron Device Lett. 31(8), 827 (2010).

${ }^{15}$ X. Zou, G. J. Fang, J. W. Wan, X. He, H. N. Wang, N. S. Liu, H. Long, and X. Z. Zhao, IEEE Trans. Electron Devices 58(7), 2003 (2011).

${ }^{16}$ Z. Q. Yao, S. L. Liu, L. Zhang, B. He, A. Kumar, X. Jiang, W. J. Zhang, and G. Shao, Appl. Phys. Lett. 101(4), 042114 (2012).

${ }^{17}$ E. Ruiz, S. Alvarez, P. Alemany, and R. A. Evarestov, Phys. Rev. B 56(12), 7189 (1997)

${ }^{18}$ J. E. Medvedeva, in Transparent Electronics: From Synthesis to Applications, edited by A. Facchetti and T. J. Marks (John Wiley \& Sons, West Sussex, 2010), p. 1.

${ }^{19}$ E. Fortin and F. L. Weichman, Can. J. Phys. 44(7), 1551 (1966).

${ }^{20}$ B. S. Li, K. Akimoto, and A. Shen, J. Cryst. Growth 311(4), 1102 (2009).

${ }^{21}$ Y. S. Gong, C. Lee, and C. K. Yang, J. Appl. Phys. 77(10), 5422 (1995).

${ }^{22}$ G. Papadimitropoulos, N. Vourdas, V. E. Vamvakas, and D. Davazoglou, Thin Solid Films 515(4), 2428 (2006).

${ }^{23}$ Z. Zang, A. Nakamura, and J. Temmyo, Mater. Lett. 92, 188 (2013).

${ }^{24}$ K. Matsuzaki, K. Nomura, H. Yanagi, T. Kamiya, M. Hirano, and H. Hosono, Appl. Phys. Lett. 93(20), 202107 (2008).

${ }^{25}$ E. Fortunato, V. Figueiredo, P. Barquinha, E. Elamurugu, R. Barros, G. Goncalves, S.-H. K. Park, C.-S. Hwang, and R. Martins, Appl. Phys. Lett. 96(19), 192102 (2010).

${ }^{26}$ S.-Y. Sung, S.-Y. Kim, K.-M. Jo, J.-H. Lee, J.-J. Kim, S.-G. Kim, K.-H. Chai, S. J. Pearton, D. P. Norton, and Y.-W. Heo, Appl. Phys. Lett. 97(22), 222109 (2010).

${ }^{27}$ A. Bashir, P. H. Wobkenberg, J. Smith, J. M. Ball, G. Adamopoulos, D. D. C. Bradley, and T. D. Anthopoulos, Adv. Mater. 21(21), 2226 (2009).

${ }^{28}$ G. Adamopoulos, S. Thomas, P. H. Wobkenberg, D. D. C. Bradley, M. A. McLachlan, and T. D. Anthopoulos, Adv. Mater. 23(16), 1894 (2011).

${ }^{29}$ T. Kosugi and S. Kaneko, J. Am. Ceram. Soc. 81(12), 3117 (1998).

${ }^{30}$ N. Serin, Semicond. Sci. Technol. 20, 398 (2005).

${ }^{31}$ M. T. S. Nair, L. Guerrero, O. L. Arenas, and P. K. Nair, Appl. Surf. Sci. 150(1-4), 143 (1999).

${ }^{32}$. F. Biccari, Ph.D. dissertation, Sapienza-University of Rome, 2009.

${ }^{33}$ O. Madelung, Semiconductors: Data Handbook, 3rd ed. (Springer, New York, 2004).

${ }^{34}$ B. A. Gizhevskii, Y. Sukhorukov, A. S. Moskvin, N. N. Loshkareva, and E. V. Mostovshchikova, J. Exp. Theor. Phys. 102(2), 297 (2006).

${ }^{35}$ J. Sohn, S.-H. Song, D.-W. Nam, I.-T. Cho, E.-S. Cho, J.-H. Lee, and H.-I. Kwon, Semicond. Sci. Technol. 28(1), 015005 (2013).

${ }^{36}$ H. Nagai, T. Suzuki, H. Hara, C. Mochizuki, I. Takano, T. Honda, and M. Sato, Mater. Chem. Phys. 137(1), 252 (2012).

${ }^{37}$ M. Izaki, T. Shinagawa, K.-T. Mizuno, Y. Ida, M. Inaba, and A. Tasaka, J. Phys. D: Appl. Phys. 40, 3326 (2007). 